\title{
Research Paper \\ Effect of Maternal Training Before and During Pregnancy on the Lipid Profile in Wistar Rat Offspring
}

Reihaneh Mohammadkhani ${ }^{1}$, ${ }^{* H a m i d}$ Rajabi $^{1}\left(\mathbb{D}\right.$, Neda Khaleghi $^{1}$, Alireza Komaki ${ }^{2}$, Iraj Salehi ${ }^{2}$

1. Department of Exercise Physiology, Faculty of Physical Education and Sports Sciences, kharazmi University, Tehran, Iran.

2. Department of Physiology, Research Center of Neurophysiology, Faculty of Medicine, Hamedan University of Medical Sciences, Hamedan, Iran.

\begin{tabular}{|l|l}
$\begin{array}{c}\text { Use your device to scan } \\
\text { and read the article online }\end{array}$ & $\begin{array}{l}\text { Citation Mohammadkhani R, Rajabi H, Khaleghi N, Komaki A, Salehi I. [Effect of Maternal Training Before and During Pregnancy } \\
\text { on the Lipid Profile in Wistar Rat Offspring (Persian)]. Jundishapur Journal of Medical Sciences. 2021; 20(5):412-423. https://doi. } \\
\text { org/10.32598/JSMJ.20.5.2131 }\end{array}$ \\
dol https://doi.org/10.32598/JSMJ.20.5.2131
\end{tabular}

Received: 02 Apr 2021 Accepted: 25 May 2021 Available Online: 01 Dec 2021

Keywords:

High-intensity-interval Training, Maternal Exercise, Offspring, Pregnancy

\section{A B STRACT}

Background and Objectives The fetal period is an important stage in a person's life. Exercise during pregnancy has been considered as a positive factor in preventing chronic diseases in adulthood. The aim of this study was to investigate the role of maternal high intensity exercise before and during pregnancy on serum levels of lipid profile of adult offspring.

Subjects and Methods Twenty-four rats (170-200g) were divided into three maternal groups: Control (C), exercise Before Pregnancy (BP) and exercise before and during pregnancy (BDP). Exercise performed before pregnancy for six weeks and during pregnancy for three weeks; one minute with $80 \%-95 \%$ vo $\max$ switching with two minutes of active recovery (65\% vo2max) for five days/week. After end of the training birth process and breastfeeding, the offspring were divided according to theirs's mother group and they were kept until adult age. The serum levels of LDL, HDL, TG and Cho were measured by enzymic method. Results The one-way ANOVA result showed that maternal exercise before and during pregnancy significantly reduced $L D L, C h o$ and $L D L / H D L$ cholesterol ratio in male $(P=0.03, P=0.2, P=0.04)$ and female $(\mathrm{P}=0.00, \mathrm{P}=0.02, \mathrm{P}=0.04)$ offspring.

Conclusion This finding suggests that maternal high-intensity-interval training as an appropriate environmental intervention can help to improve the health of the next generation.

\section{* Corresponding Author:}

Hamid Rajabi, PhD.

Address: Department of Exercise Physiology, Faculty of Physical Education and Sports Sciences, kharazmi University, Tehran, Iran.

Tel: +98 (912) 7937768

E-Mail: hrajabi1346@gmail.com 


\title{
اثر تمرين مادرى قبل و هنكام باردارى بر يروفايل لييبدى فرزندان موشهاى صحر ايى ثراد ويستار
}

\author{
ريحانه محمدخانى' (1)، "حميد رجبى' (1)، ندا خالدى'، عليرضا كمكى' (1)، ايرج صالحى

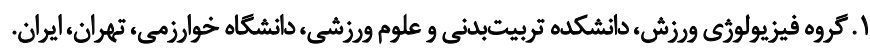

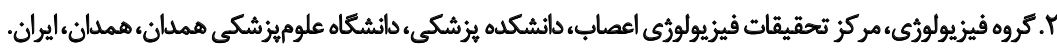

\section{جيكيد}

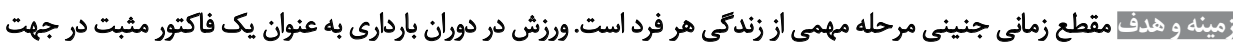

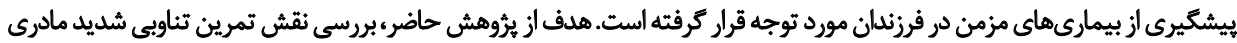

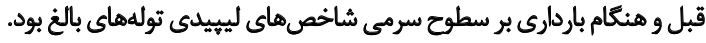

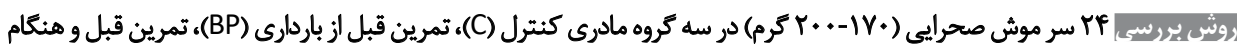

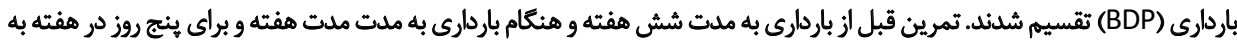

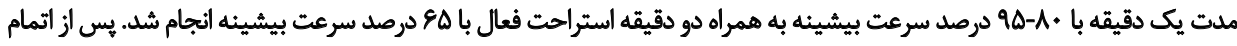

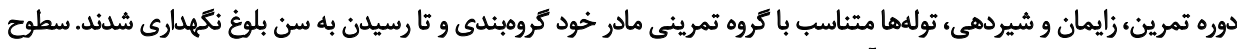

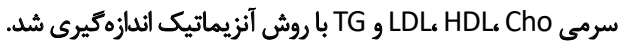

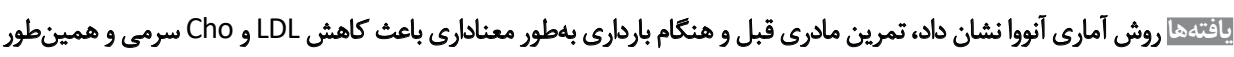

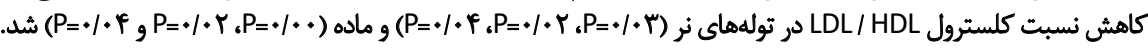

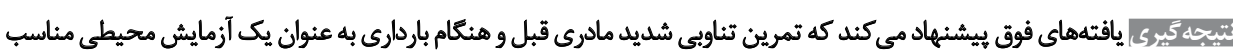

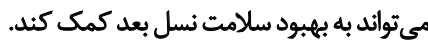

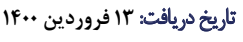

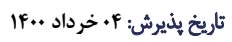

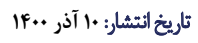

كليuوlog

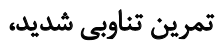
تمرين مادرى، فرزندان، تمرين باردارى تمرين

همينطور شواهد رو به رشدى نشان مي دهد كه وضعيت بدني

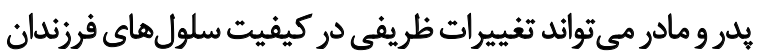

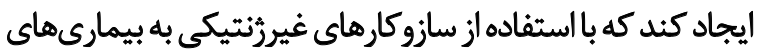

مزمن در فرزندان منجر شود [Y. F.

علاوه بر مرحله جنيني، ارتقاى سلامت مادر قبل از باردارى

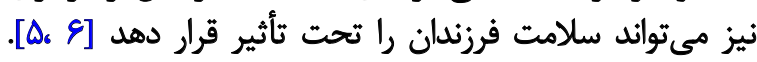

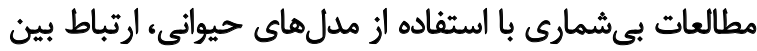

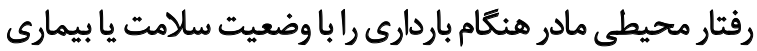

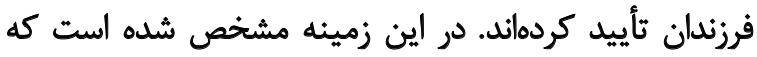

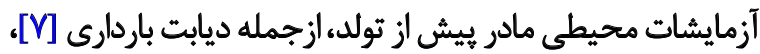

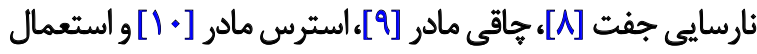

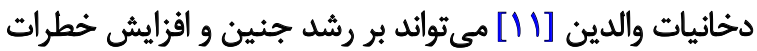

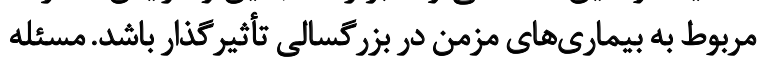

مقلمa مقطع زمانى جنينى مرحله مهمى از زندكى هر فرد است

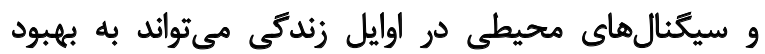

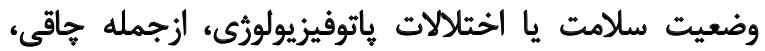

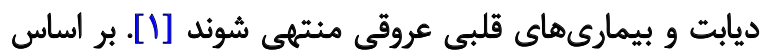

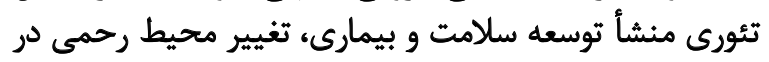

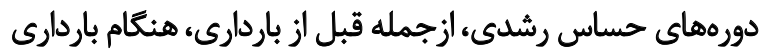

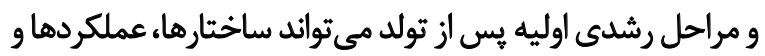

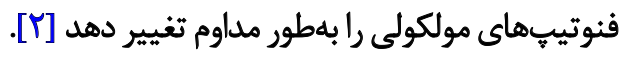

مطالعات قبلى نشان مي دهند كه محيط جنينى و زندكى نوزاد

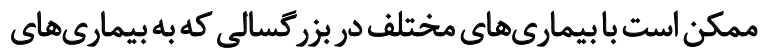

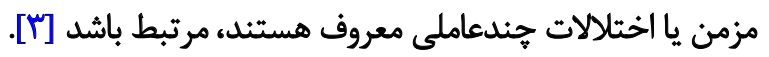

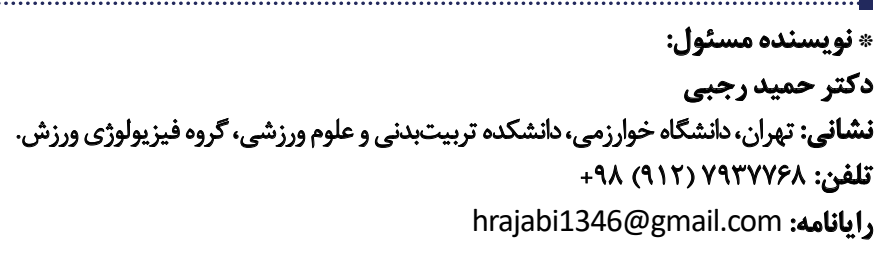




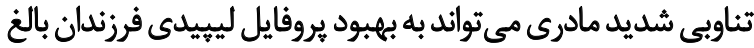

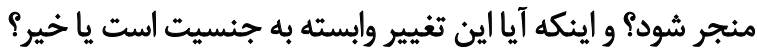

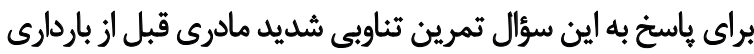

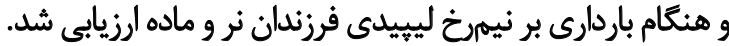

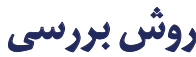

يخوهش حاضر از نوع توسعهاى و روش آن تجربي بود و در در بخش فيزيولوزى دانشكده يزشكى دانشعاه علوميز توشكى همدان انجام شد.

نمونههاى حيوانى ثرؤهش: TF سر موش صحرايى ماده

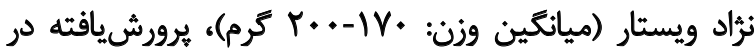

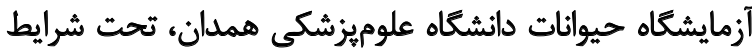

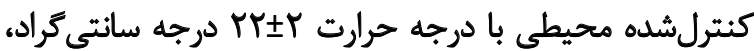

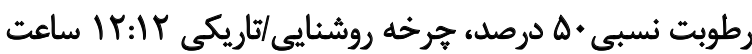

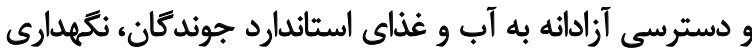

شدند.

طراحى مطالعه: حيوانات مطالعهشده در اين آزمايش بهطور

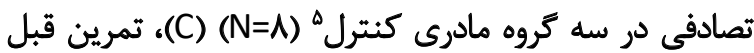

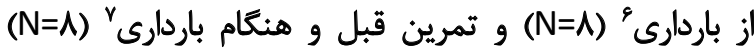

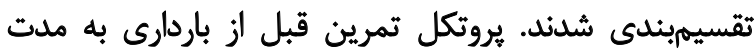

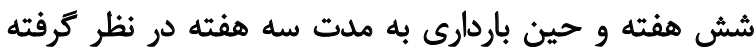

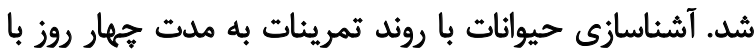

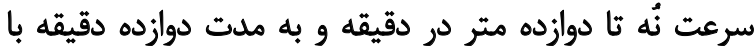

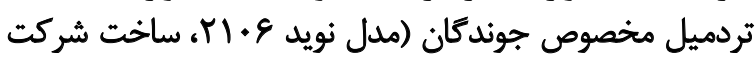
تجهيز كستر اميد ايرانى) انجام شدون (مدل نون

به منظور ارزيابى حداكثر ظرفيت دويدن براي تعيين سرعت

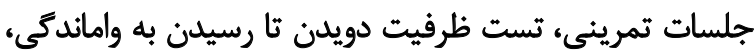

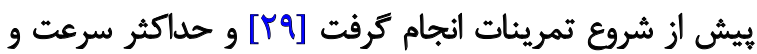

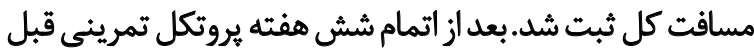

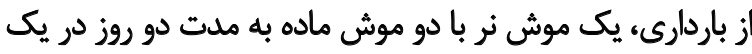

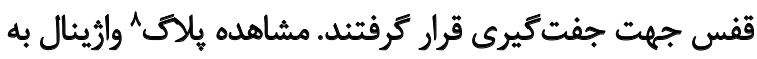

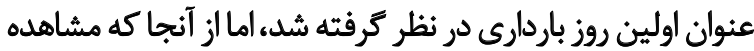

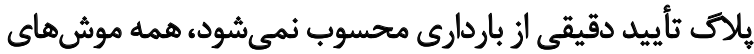

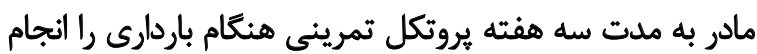

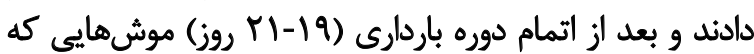
باردار نشده بودند، از مطالعه خارج شدند.

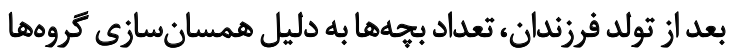

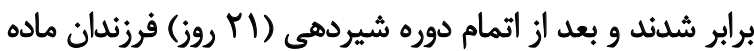

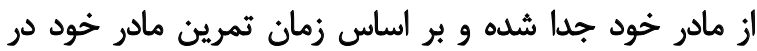

\section{Control}

6. Before Pregnancy (BP)

7. Before and During Pregnancy (BDP)

8. Plug
قابل تأمل اين است كه در بيشتر مطالعات نقش مداخلات منفى

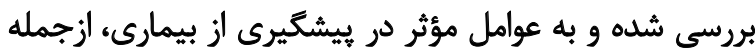

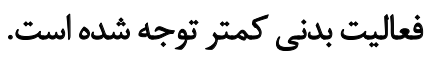

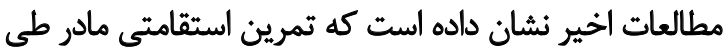

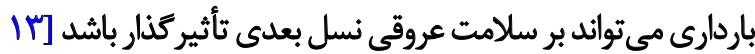

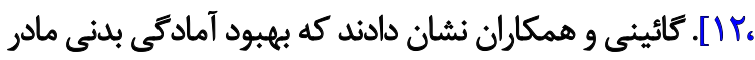

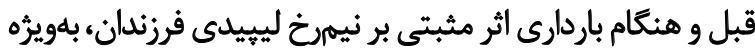

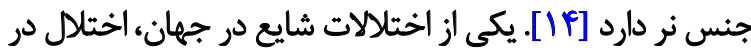

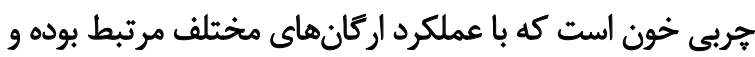

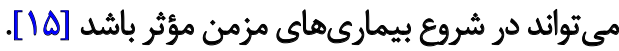
به خوبى مشخص شده است كه يكى از نشانهاي بيمارى

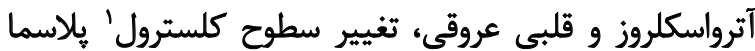

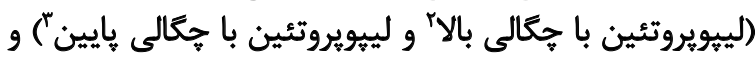

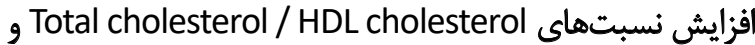
است [19LL / HDL cholesterol.

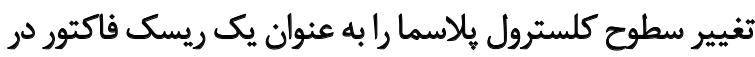

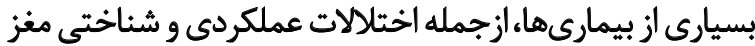

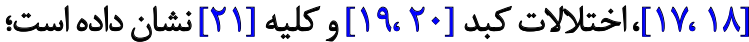

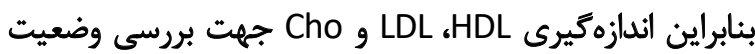
سلامت بدن اهميت بسزايى دارد [ [TY].

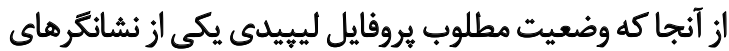

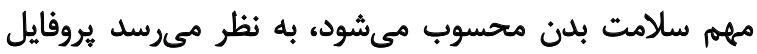



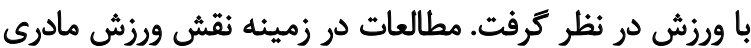

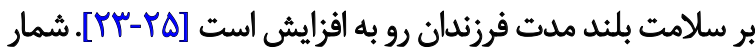

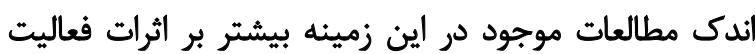

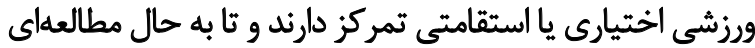

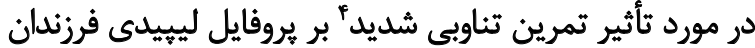

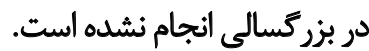

تمرين تناوبى شديد به عنوان وهلههاي تكرارى فعاليت ورزشى

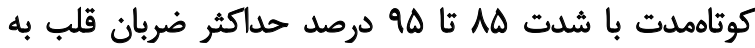

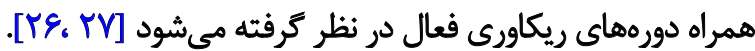

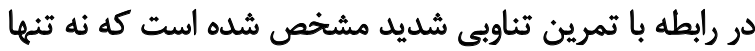

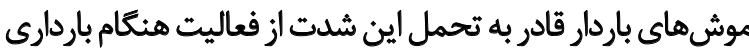

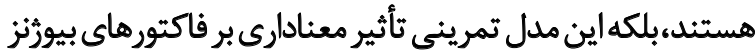

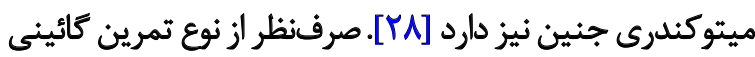

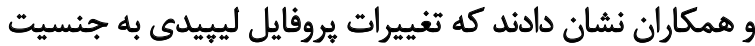

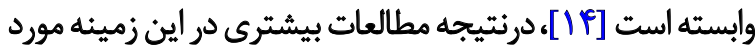
نياز است. بنابراين سؤال اصلى اين مطالعه اين است كه آيا تمرين مين موردين

1. Cholestero

2. High-density Lipoprotein

3. Low-density Lipoprotein

4. High-intensity-interval Training 
است. در شروع تمرينات تفاوت معنادارى در وزن مادران بين

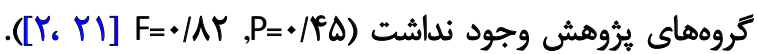

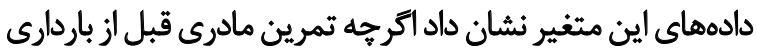

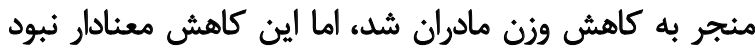

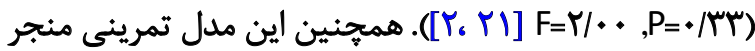

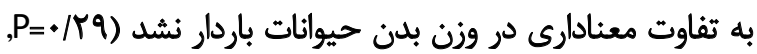

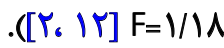

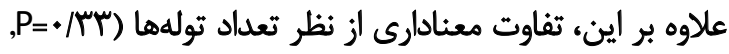

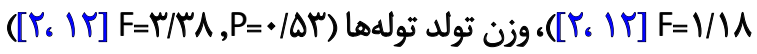

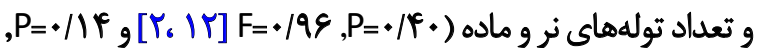

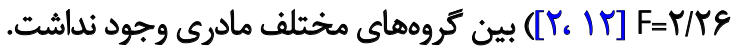

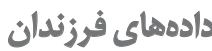

يافتههاي حاصل از تجزيه و تحليل دادههاي موجود در رابطه

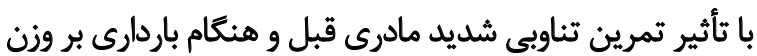

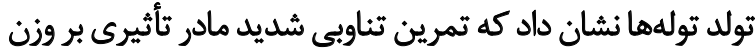

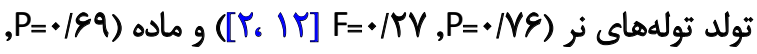

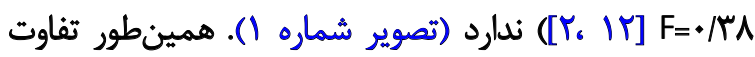

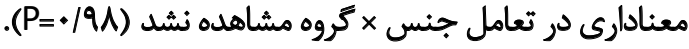

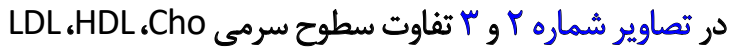

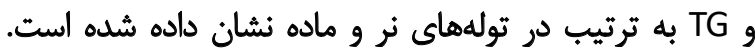

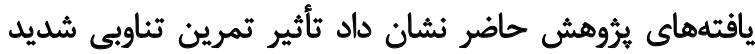

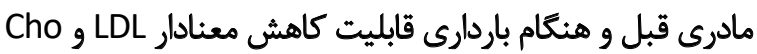

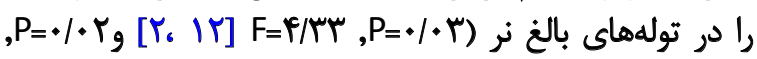

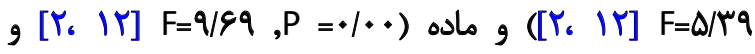

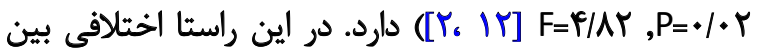

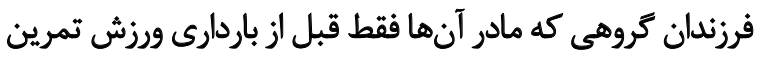

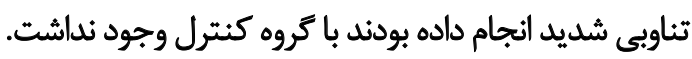
در تصاوير شماره F و ه ميزان نسبت كلسترول تام به كلسترول

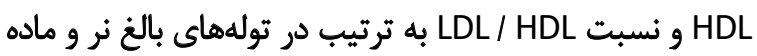

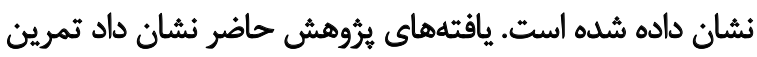

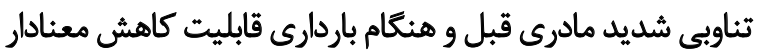

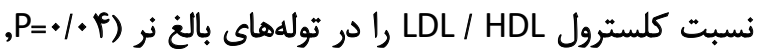

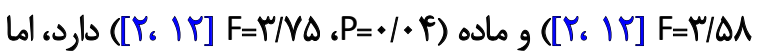

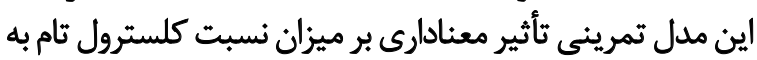

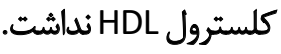

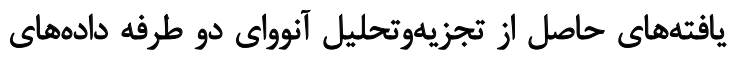

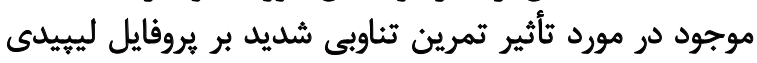

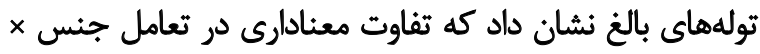

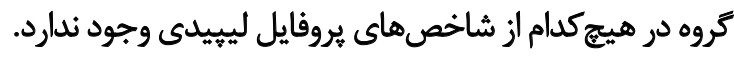

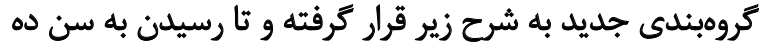

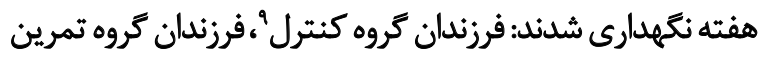

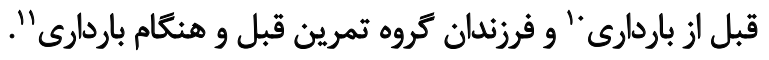

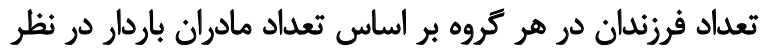
كرفته شد.

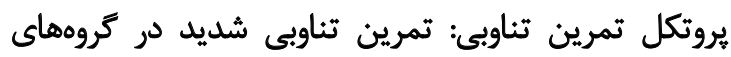

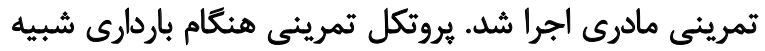



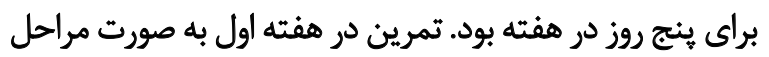

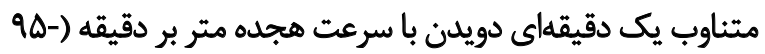

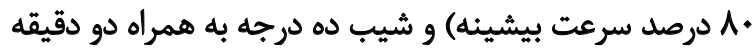

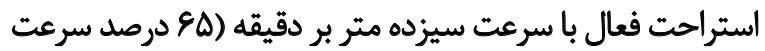

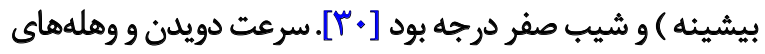
تمرينى به ازاى هر هفته بر اساس اصل اضافه بار افزايش يافت (جدول شماره 1).

تهيه نمونه: بعد از دوازده ساعت ناشتايى، وزن نهايى حيوانات

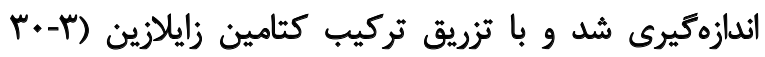

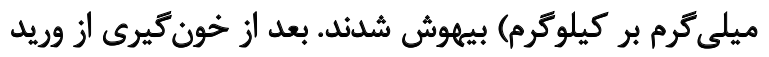

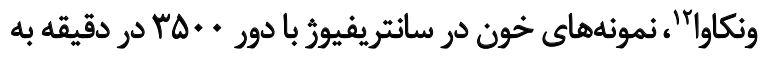

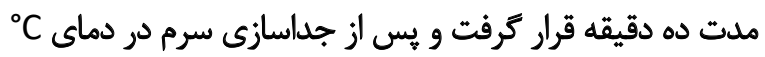

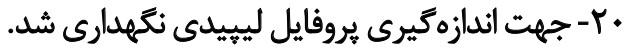

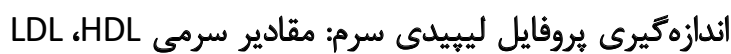

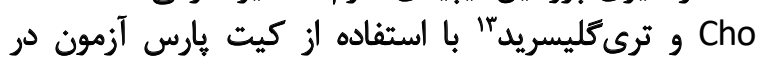
آزمايشعاه رفرانس همدان توسط دستكاه اتوآنالايزر اندازهكيرى آزون دري شُ شد. روشهاى آمارى: در يروهش حاضر همه اطلاعات به صورت

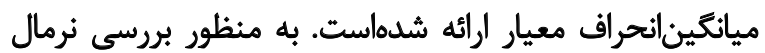

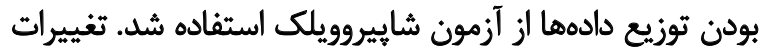

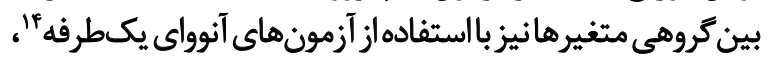

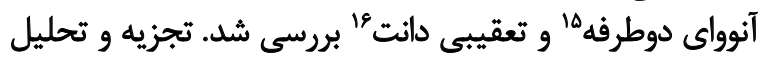

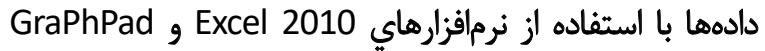

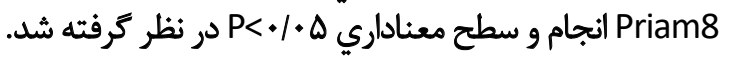

يافتهها

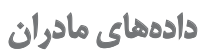
دادههاى توصيفى مادران در جدول شماره Y نشان داده شده

9. Pups of Control Group (Pc)

10. Pups of Before Pregnancy (PbP)

11. Pups of Before and During Pregnancy (PbdP)

12. Vena Cava

13. Triglyceride (TG)

14. One-way ANOVA

15. Two-way ANOVA

16. Dunnett 


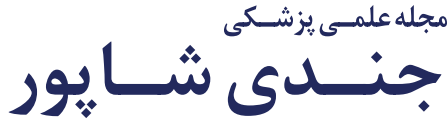

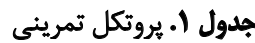

\begin{tabular}{|c|c|c|c|c|}
\hline \multicolumn{5}{|c|}{ يروتكل تمرينى قبل از بارهارى } \\
\hline زمان كل تمرين & تعداد وهلهها: & سرعت استراحت فعال (متر بر دقيقه) با يا بدون شيب & سرعت بيشينه (متر بر دقيقه) با شيب + ا درجه & هفته \\
\hline$r$ & 1. & ir & M & 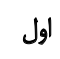 \\
\hline$\pi$ & 11 & ir & M & 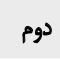 \\
\hline re & ir & if & r. & 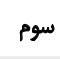 \\
\hline rq & ir & 18 & $\pi$ & جهارم \\
\hline m & if & M & $\pi$ & ينجم:م \\
\hline Pa & 10 & r. & re & 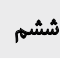 \\
\hline \multicolumn{5}{|c|}{ يروتكل تمرينى هنكام باردارى } \\
\hline$r+$ & 1. & ir & in & 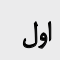 \\
\hline$r$ & 11 & ir & in & دوم \\
\hline re & ir & If & r. & سوم \\
\hline
\end{tabular}

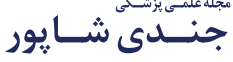

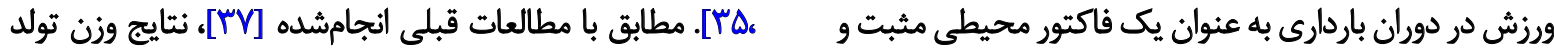

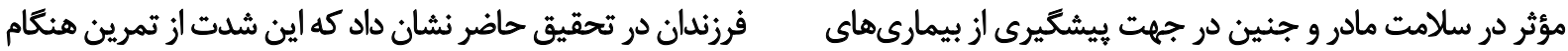

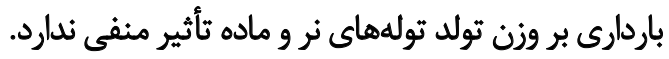

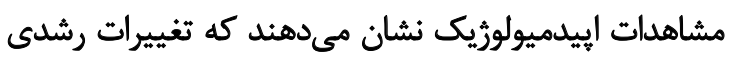

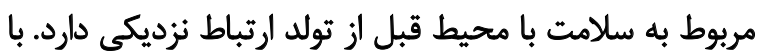

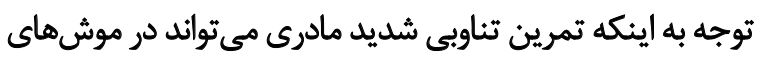

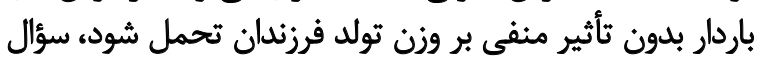

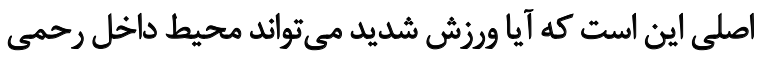

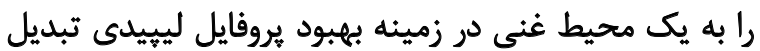

بر اساس بيشينه تحقيق، تا به امروز تنها يكى مطالعه، تأثير

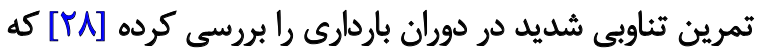

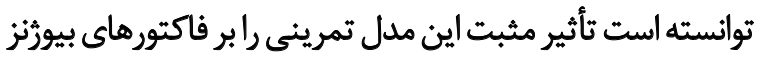

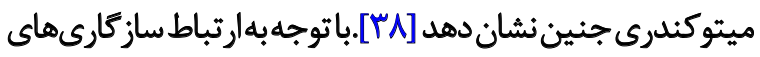

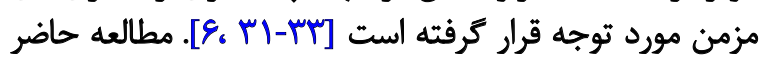

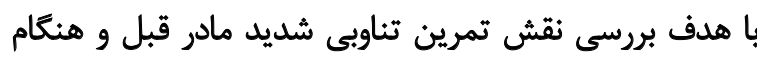

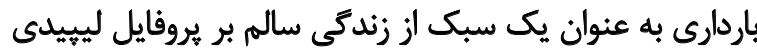
فرزندان انجام شد.

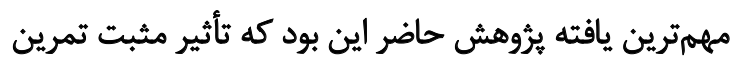

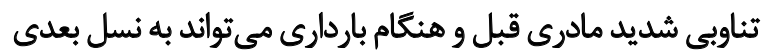



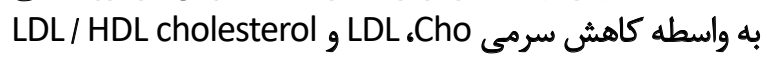
محافظت كند. اين تأثيرات در هر دو جنس يكسان هستند. شواهد علمى مختلف از رابطه وزن تولد بر بيامدهاي سلامت

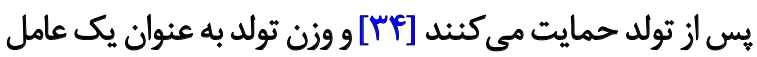

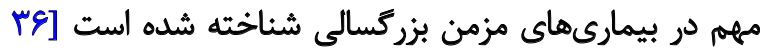

جدول Y. مشخصات توصيفى مادران

\begin{tabular}{|c|c|c|c|}
\hline C & BP & BDP & مشخصات توصيفى \\
\hline$\Delta$ & 8 & r & تعلداد موش شهاي باردارشئه \\
\hline $\mathrm{V} \pm \cdot / 9 \mathrm{r}$ & $\Delta \pm \backslash M$ & $q \pm . / 4$ & تعداد تولههاى هر موش (ميانكين+|نحر افـمعيار) \\
\hline$f$ & r & $\Delta$ & توزيع جنسيثتي \\
\hline r & r & $F$ & 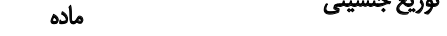 \\
\hline
\end{tabular}

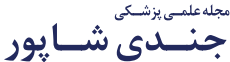

كروه C: مادرائى كه تمرين نكردند (كنترل)؛ كروه BP: مادراني كه قبل از باردارى ورزش كردند؛ كروه BDP: مادرانى كه قبل و هنكام باردارى تمرين كردند. 


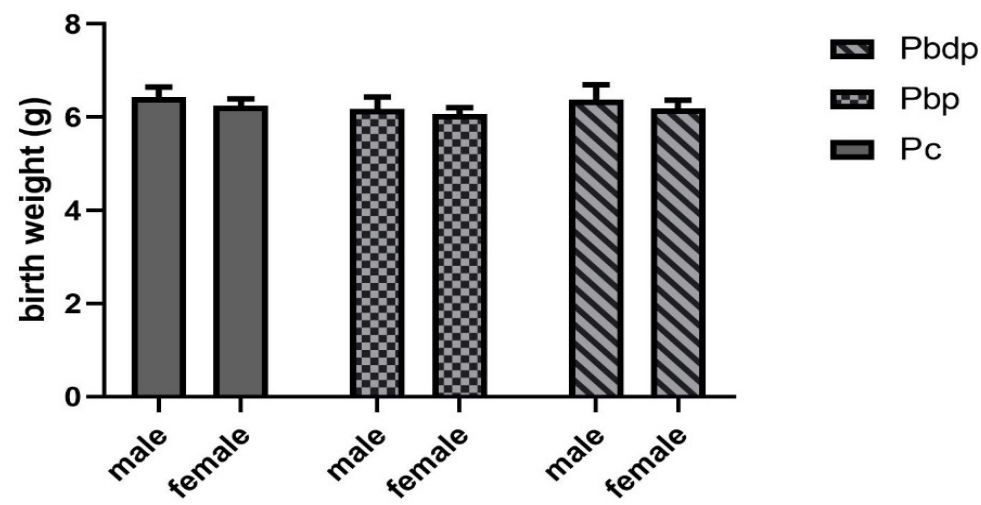

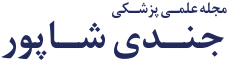

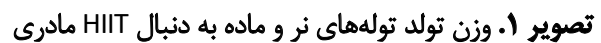

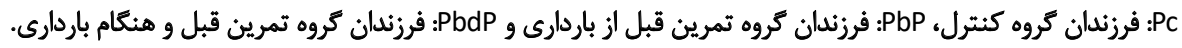

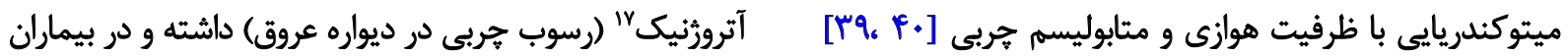

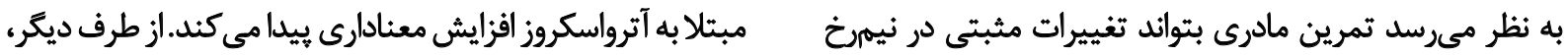

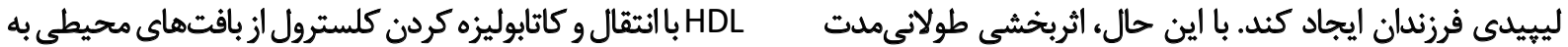

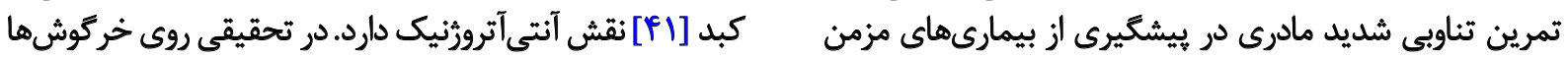

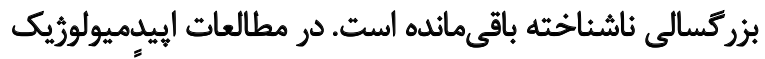
17. Atherogenic

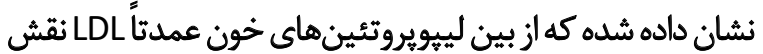
توله هاى نز
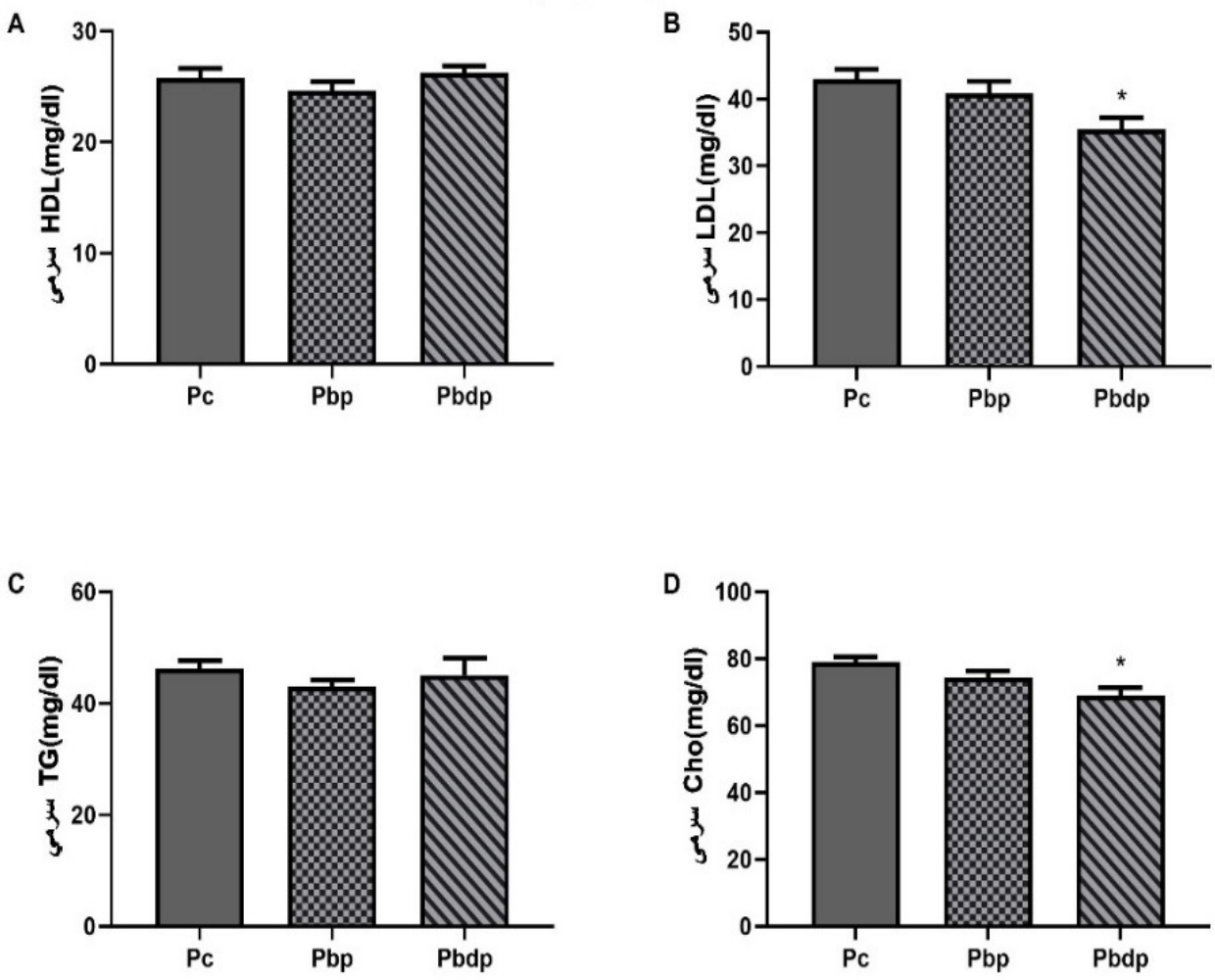

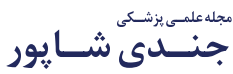

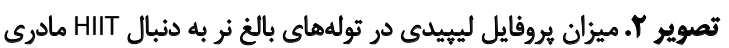

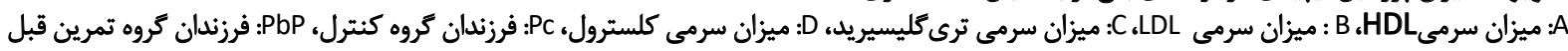

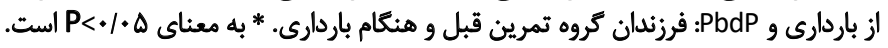



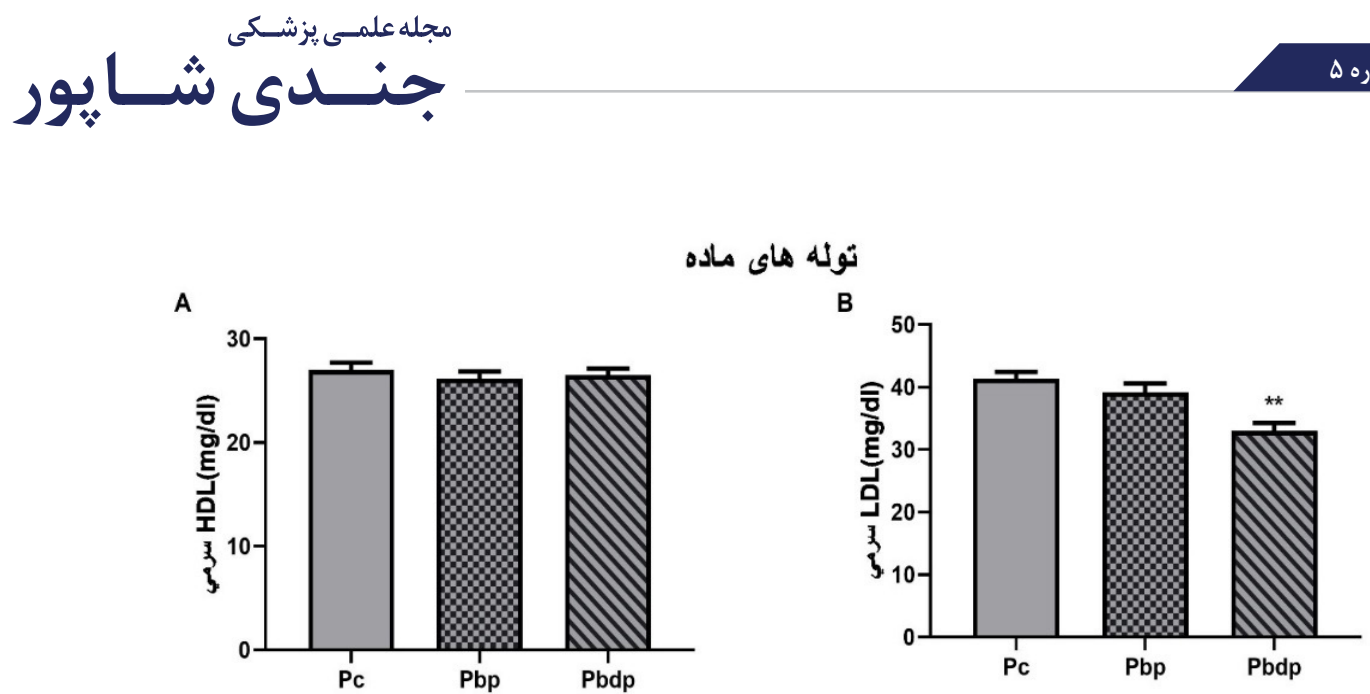

C

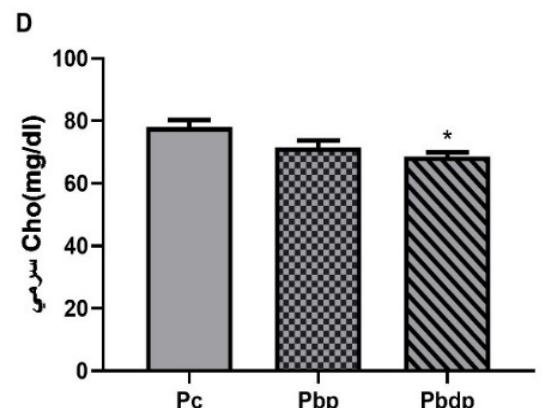

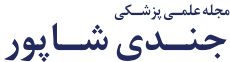

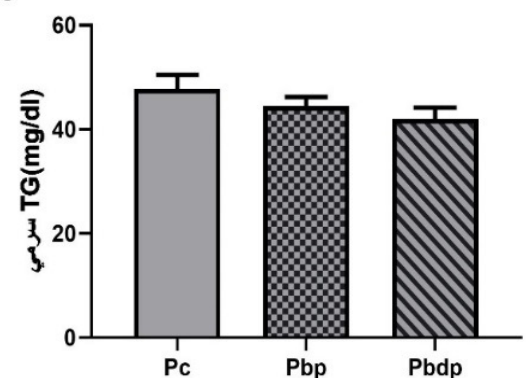

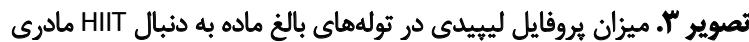

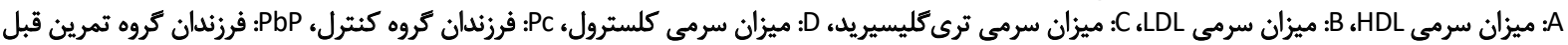

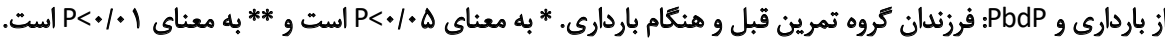

متفاوتى در رابطه با تأثير رفتار مادر هنكام باردارى بر بروفائيل

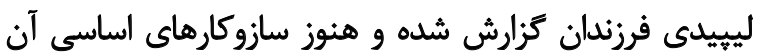
مشخص شد كه آزمايشات كاهنده كلسترول در دوران باردارى،

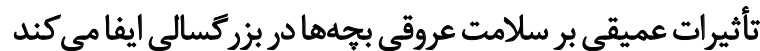

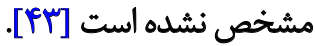

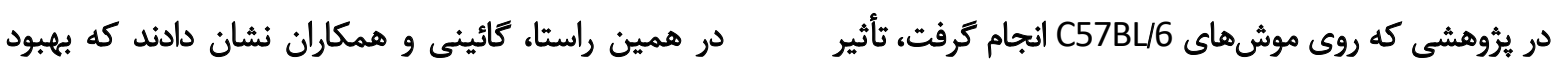

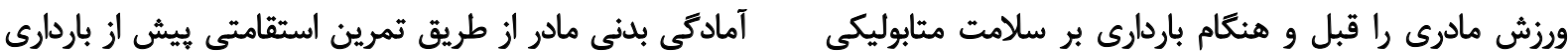

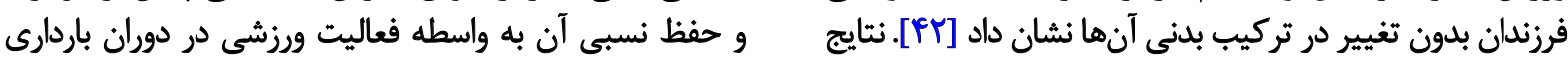

توله هاى نر

A

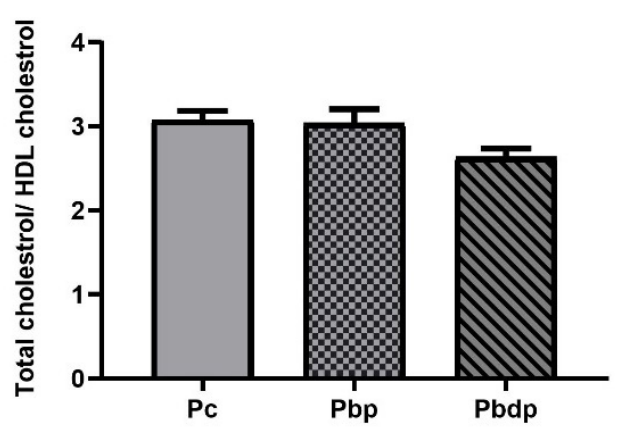

B

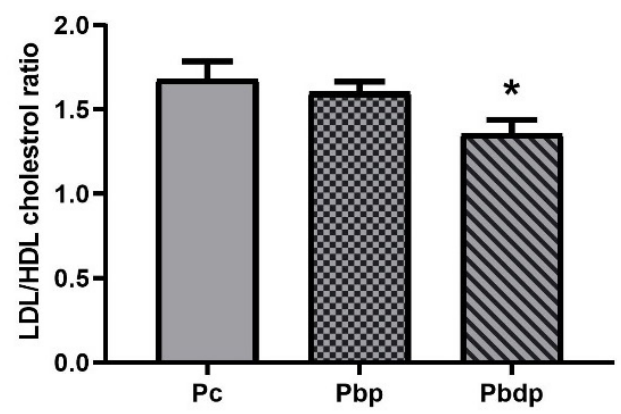

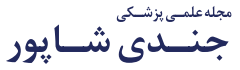

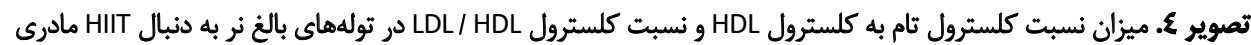

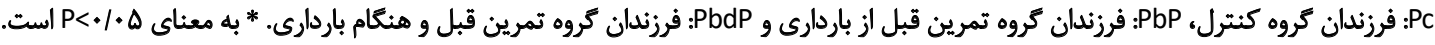




\section{توله هاى ماده}

A

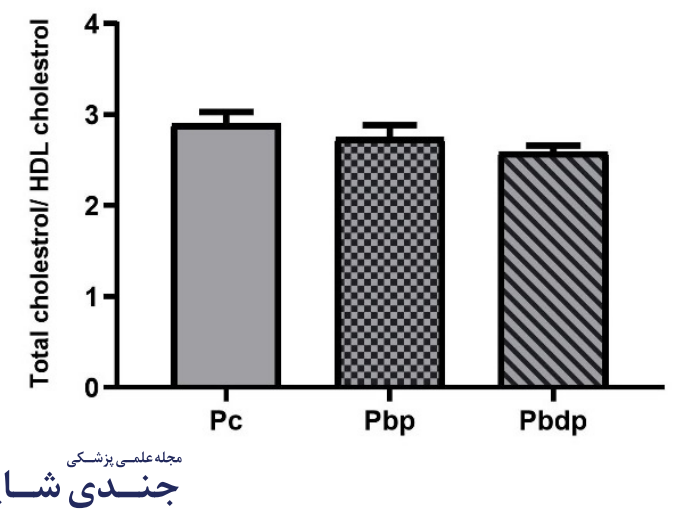

B

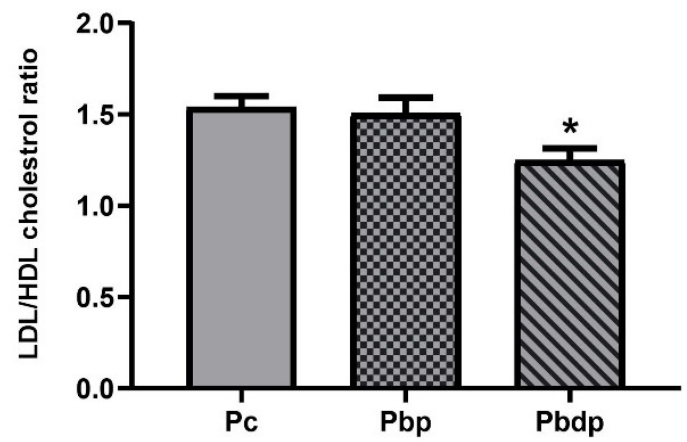

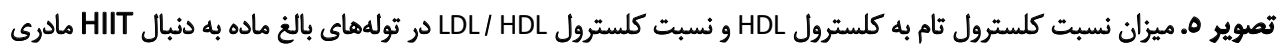

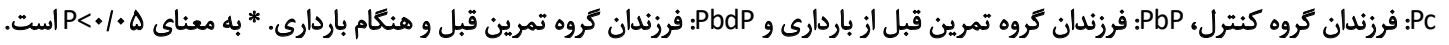

تام به HDL شد، اما اين كاهش معنادار نبود.

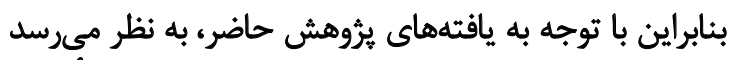

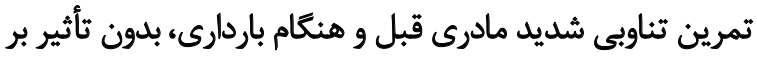

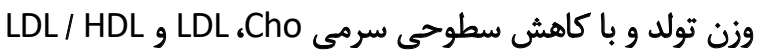
cholesterol

باعث تولد فرزندانى سالم در بزرخالى شورد

$$
\text { نتيجهي كيرى }
$$

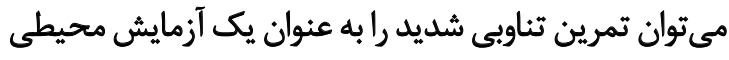

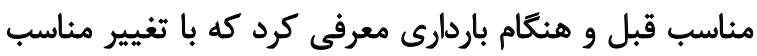

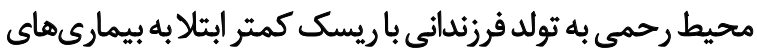
مزمن در بزركسالى كمك مي كند.

ملاحظات اخلاقى

\section{ي بيروى از اصول الخالق ثيثوهش}

تمام آزمايشات حيوائى بر اساس دستور العمل هائ انجمن ملى إنى

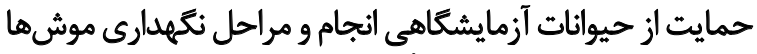

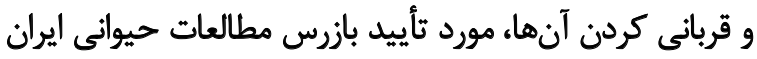

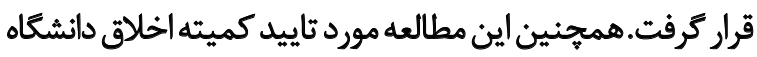

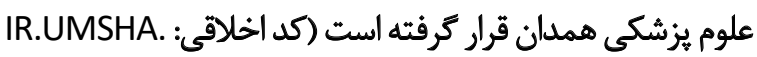
(REC 1397.528

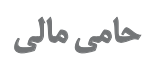

اين مقاله بركرفته از رساله دكترى نويسنده اول در كرون

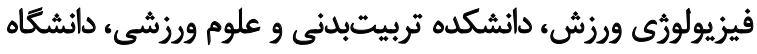

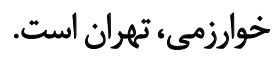

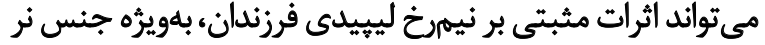

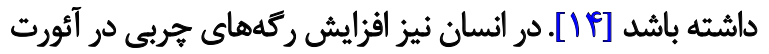

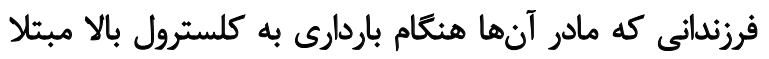

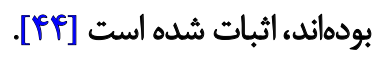

در اين راستاه نتايج مطالعه حاضر نشان داد تمرين تناوبى شديد

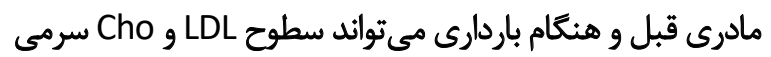

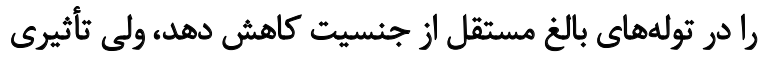

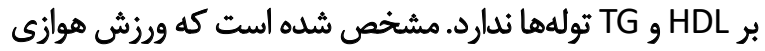

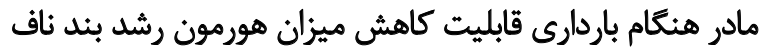

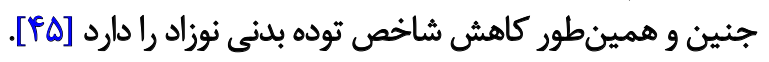

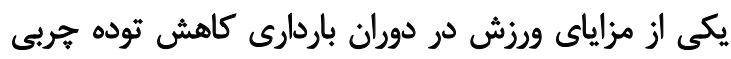

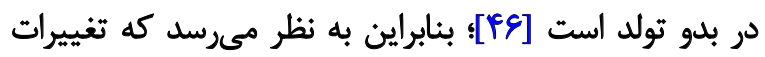

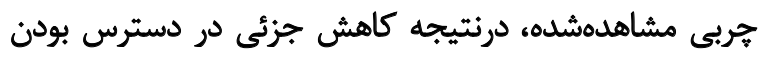

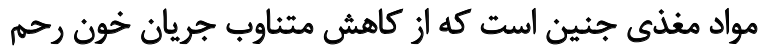

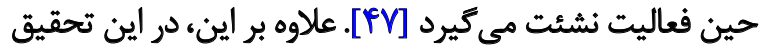
تمرين تناوبى شديد مادرى نتوانست ميزان

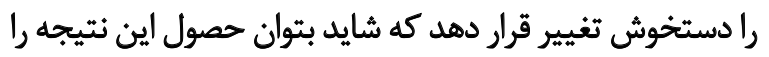

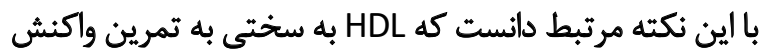

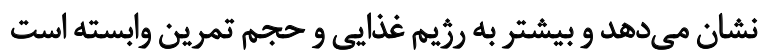

[F [ $\left.F \lambda_{6} F q\right]$

Total cholesterol / HDL با توجه به اهميت نسبتهاى

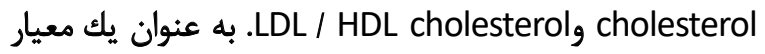

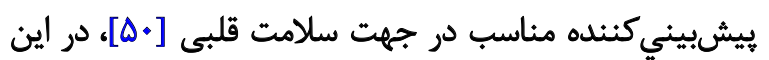

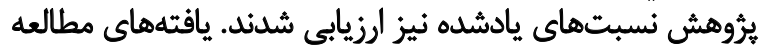

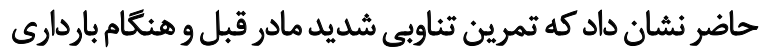



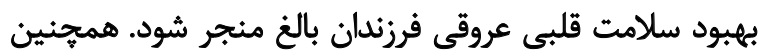

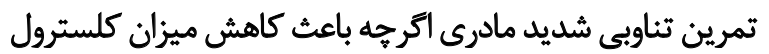




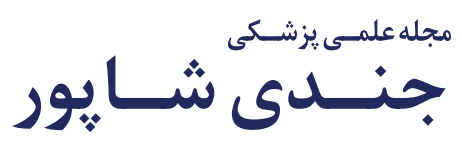

$$
\begin{aligned}
& \text { مشاركث ثويسندكًان } \\
& \text { تمامتى نويسندكًان به يك اندازه در نكارش مقاله مشاركت } \\
& \text { تعارض مناقع }
\end{aligned}
$$

بنابر اظهار نويسندكان اين مقاله تعارض منافع ندارد. 


\section{References}

[1] Bernal AB, Vickers MH, Hampton MB, Poynton RA, Sloboda DM. Maternal undernutrition significantly impacts ovarian follicle number and increases ovarian oxidative stress in adult rat offspring. PLoS One. 2010; 5(12):e15558. [DOI:10.1371/journal.pone.0015558] [PMID] [PMCID]

[2] Moczek AP, Sultan S, Foster S, Ledón-Rettig C, Dworkin I, Nijhout $\mathrm{HF}$, et al. The role of developmental plasticity in evolutionary innovation. Proc Biol Sci. 2011; 278(1719):2705-13. [DOI:10.1098/rspb.2011.0971] [PMID] [PMCID]

[3] Li X, Zhang M, Pan X, Xu Z, Sun M. “Three Hits" hypothesis for developmental origins of health and diseases in view of cardiovascular abnormalities. Birth Defects Res. 2017; 109(10):74457. [DOI:10.1002/bdr2.1037] [PMID]

[4] Velazquez M, Smith C, Smyth N, Osmond C, Fleming T. Advanced maternal age causes adverse programming of mouse blastocysts leading to altered growth and impaired cardiometabolic health in post-natal life. Hum Reprod. 2016; 31(9):197080. [DOI:10.1093/humrep/dew177] [PMID] [PMCID]

[5] Gaeini AA, Shafiei Neek L, Choobineh S, Baghaban Eslaminejad $M$, Satarifard S, Sayahpour FA, et al. Preconception endurance training with voluntary exercise during pregnancy positively influences on remodeling markers in female offspring bone. J Matern Fetal Neonatal Med. 2016; 29(22):3634-40. [DOI:10.3 109/14767058.2016.1140140] [PMID]

[6] Liu J, Lee I, Feng H-Z, Galen SS, Hüttemann PP, Perkins GA, et al. Aerobic exercise preconception and during pregnancy enhances oxidative capacity in the hindlimb muscles of mice offspring. J Strength Cond Res. 2018; 32(5):1391-403. [DOI:10.1519/JSC.0000000000002416] [PMID] [PMCID]

[7] West N, Crume T, Maligie M, Dabelea D. Cardiovascular risk factors in children exposed to maternal diabetes in utero. Diabetologia. 2011; 54(3):504-7. [DOI:10.1007/s00125-010-20081] [PMID] [PMCID]

[8] Dodson RB, Rozance PJ, Fleenor BS, Petrash CC, Shoemaker LG, Hunter KS, et al. Increased arterial stiffness and extracellular matrix reorganization in intrauterine growth-restricted fetal sheep. Pediatr Res. 2013; 73(2):147-54. [DOI:10.1038/ pr.2012.156] [PMID] [PMCID]

[9] Gademan MG, van Eijsden M, Roseboom TJ, van der Post JA, Stronks K, Vrijkotte TG. Maternal prepregnancy body mass index and their children's blood pressure and resting cardiac autonomic balance at age 5 to 6 years. Hypertension. 2013; 62(3):641-7. [DOI:10.1161/HYPERTENSIONAHA.113.01511] [PMID]

[10] Seng JS, Low LK, Sperlich M, Ronis DL, Liberzon I. Post-traumatic stress disorder, child abuse history, birthweight and gestational age: A prospective cohort study. BJOG. 2011; 118(11):1329-39. [DOI:10.1111/j.1471-0528.2011.03071.x] [PMID] [PMCID]

[11] Ko T-J, Tsai L-Y, Chu L-C, Yeh S-J, Leung C, Chen C-Y, et al. Parental smoking during pregnancy and its association with low birth weight, small for gestational age, and preterm birth offspring: A birth cohort study. Pediatr Neonatol. 2014; 55(1):207. [DOI:10.1016/j.pedneo.2013.05.005] [PMID]
[12] Boonpattrawong N, Golbidi S, Laher I, Devlin A. Maternal exercise improves glucose homeostasis and vascular health in male offspring. Atheroscler Suppl. 2018; 32:16. [DOI:10.1016/j.atherosclerosissup.2018.04.048]

[13] Boonpattrawong N, Tai D, Aleliunas R, Devlin A. Maternal obesity and exercise programs cardiovascular health in offspring. Can J Cardiol. 2016; 32(10):S233. [DOI:10.1016/j.cjca.2016.07.374]

[14] Gaeini AA, Shafiei Neek L, Choobineh S, Baghaban Eslaminejad $M$, Satarifard S, Mousavi SN. [The effects of the preconception endurance exercise training and voluntary exercise activity during pregnancy in C57BL/6 mice on lipid profile of the adult offspring (Persian)]. Arak Med Univ J. 2016; 19(107):68-79. http:// jams.arakmu.ac.ir/article-1-4041-.pdf

[15] WHO. Global tuberculosis report 2013. Geneva: World Health Organization; 2013. https://apps.who.int/iris/handle/10665/91355

[16] Lichtenstein AH, Appel $L$, Brands $M$, Carnethon M, Daniels $\mathrm{S}$, Franch HA, et al. Summary of American Heart Association diet and lifestyle recommendations revision 2006. Arterioscler Thromb Vasc Biol. 2006; 26(10):2186-91. [DOI:10.1161/01. ATV.0000238352.25222.5e] [PMID]

[17] Ryu W-S, Schellingerhout D, Jeong S-W, Nahrendorf M, Kim D-E. Association between serum lipid profiles and early neurological deterioration in acute ischemic stroke. J Stroke Cerebrovasc Dis. 2016; 25(8):2024-30. [DOI:10.1016/j.jstrokecerebrovasdis.2016.05.009] [PMID]

[18] Weinstock-Guttman B, Zivadinov R, Mahfooz N, Carl E, Drake A, Schneider J, et al. Serum lipid profiles are associated with disability and MRI outcomes in multiple sclerosis. J Neuroinflammation. 2011; 8:127. [DOI:10.1186/1742-2094-8-127] [PMID] [PMCID]

[19] Schiff L, Schubert WK, McAdams AJ, Spiegel EL, O'Donnell JF. Hepatic cholesterol ester storage disease, a familial disorder: I. clinical aspects. Am J Med. 1968; 44(4):538-46. [DOI:10.1016/00029343(68)90054-5]

[20] Taskinen M-R. Type 2 diabetes as a lipid disorder. Curr Mol Med. 2005; 5(3):297-308. [DOI:10.2174/1566524053766086] [PMID]

[21] Nazıroğlu M, Güler M, Özgül C, Saydam G, Küçükayaz M, Sözbir E. Apple cider vinegar modulates serum lipid profile, erythrocyte, kidney, and liver membrane oxidative stress in ovariectomized mice fed high cholesterol. J Membr Biol. 2014; 247(8):667-73. [DOI:10.1007/s00232-014-9685-5] [PMID]

[22] Dosti M. [Isolation of HDL-2 and HDL-3 and assesment of concentration of Cholestrol (Persian)]. Tehran Univ Med J. 1997; 55(6):7-12. http://tumj.tums.ac.ir/article-1-1606-fa.html

[23] Abdolah Pour A, Rajabi H, Gaeini AA, Sofiabadi M, Khaledi N. [The effect of aerobic exercise during pregnancy on vascular BCL$2, \mathrm{BAX}$ and eNOS gene expression in adult male offspring rat (Persian)]. Razi J Med Sci. 2019; 26(5):56-66. http://rjms.iums.ac.ir/ article-1-5430-en.html

[24] Palinski W, D'Armiento FP, Witztum JL, De Nigris F, Casanada F, Condorelli $\mathrm{M}$, et al. Maternal hypercholesterolemia and treatment during pregnancy influence the long-term progression of atherosclerosis in offspring of rabbits. Circ Res. 2001; 89(11):9916. [DOI:10.1161/hh2301.099646] [PMID] 
[25] Zarbaf R, Abdolah Pour A. [The effect of aerobic exercise before and during pregnancy on vascular BAX/ BCL-2 gene expression in adult male offspring rat (Persian)]. Jundishapur Sci Med J. 2020; 18(5):417-34. https://www.sid.ir/fa/Journal/ ViewPaper.aspx?ID=539467

[26] Haram PM, Kemi OJ, Lee SJ, Bendheim M $\varnothing$, Al-Share QY, Waldum $\mathrm{HL}$, et al. Aerobic interval training vs. continuous moderate exercise in the metabolic syndrome of rats artificially selected for low aerobic capacity. Cardiovasc Res. 2008; 81(4):723-32. [DOI:10.1093/cvr/cvn332] [PMID] [PMCID]

[27] Kemi OJ, Haram PM, Loennechen JP, Osnes J-B, Skomedal T, Wisløff $U$, et al. Moderate vs. high exercise intensity: Differential effects on aerobic fitness, cardiomyocyte contractility, and endothelial function. Cardiovasc Res. 2005; 67(1):161-72. [DOI:10.1016/j.cardiores.2005.03.010] [PMID]

[28] Songstad NT, Kaspersen K-HF, Hafstad AD, Basnet P, Ytrehus $K$, Acharya $G$. Effects of high intensity interval training on pregnant rats, and the placenta, heart and liver of their fetuses. PloS One. 2015; 10(11):e0143095. [DOI:10.1371/journal. pone.0143095] [PMID] [PMCID]

[29] Mendes OC, Sugizaki MM, Campos DS, Damatto RL, Leopoldo AS, Lima-Leopoldo AP, et al. Exercise tolerance in rats with aortic stenosis and ventricular diastolic and/or systolic dysfunction. Arq Bras Cardiol. 2013; 100(1):44-51. [DOI:10.1590/ S0066-782X2012005000112] [PMID]

[30] Freitas DA, Rocha-Vieira E, Soares BA, Nonato LF, Fonseca SR, Martins JB, et al. High intensity interval training modulates hippocampal oxidative stress, BDNF and inflammatory mediators in rats. Physiol Behav. 2018; 184:6-11. [DOI:10.1016/j.physbeh.2017.10.027] [PMID]

[31] Klein CP, dos Santos Rodrigues K, Hözer RM, de Sá CoutoPereira N, Saccomori AB, Dal Magro BM, et al. Swimming exercise before and during pregnancy: Promising preventive approach to impact offspring's health. Int J Dev Neurosci. 2018; 71:83-93. [DOI:10.1016/j.ijdevneu.2018.08.009] [PMID]

[32] Harris JE, Baer LA, Stanford KI. Maternal exercise improves the metabolic health of adult offspring. Trends Endocrinol Metab. 2018; 29(3):164-77. [DOI:10.1016/j.tem.2018.01.003] [PMID] [PMCID]

[33] Eclarinal JD, Zhu S, Baker MS, Piyarathna DB, Coarfa C, Fiorotto $\mathrm{ML}$, et al. Maternal exercise during pregnancy promotes physical activity in adult offspring. FASEB J. 2016; 30(7):25418. [DOI:10.1096/fj.201500018R] [PMID] [PMCID]

[34] Barker DJ. In utero programming of chronic disease. Clin Sci (Lond). 1998; 95(2):115-28. [DOI:10.1042/CS19980019]

[35] Beeson JH, Blackmore HL, Carr SK, Dearden L, Duque-Guimarães DE, Kusinski LC, et al. Maternal exercise intervention in obese pregnancy improves the cardiovascular health of the adult male offspring. Mol Metab. 2018; 16:35-44. [DOI:10.1016/j.molmet.2018.06.009] [PMID] [PMCID]

[36] Hopkins SA, Baldi JC, Cutfield WS, McCowan L, Hofman PL. Effects of exercise training on maternal hormonal changes in pregnancy. Clin Endocrinol (Oxf). 2011; 74(4):495-500. [DOI:10.1111/j.1365-2265.2010.03964.x] [PMID]
[37] Raipuria M, Hardy G, Bahari H, Morris M. Maternal obesity regulates gene expression in the hearts of offspring. Nutr Metab Cardiovasc Dis. 2015; 25(9):881-8. [DOI:10.1016/j.numecd.2015.05.011] [PMID]

[38] Chung E, Joiner HE, Skelton T, Looten KD, Manczak M, Reddy $\mathrm{PH}$. Maternal exercise upregulates mitochondrial gene expression and increases enzyme activity of fetal mouse hearts. Physiol Rep. 2017; 5(5):e13184. [DOI:10.14814/phy2.13184] [PMID] [PMCID]

[39] White CR, Datta G, Giordano S. High-density lipoprotein regulation of mitochondrial function. Adv Exp Med Biol. 2017; 982:407-29. [DOI:10.1007/978-3-319-55330-6_22] [PMID] [PMCID]

[40] Vega RB, Brouwers B, Parsons SA, Stephens NA, Pino MF, Hodges $A$, et al. An improvement in skeletal muscle mitochondrial capacity with short-term aerobic training is associated with changes in Tribbles 1 expression. Physiol Rep. 2020; 8(12):e14416. [DOI:10.14814/phy2.14416] [PMID] [PMCID]

[41] Schaefer EJ, Eisenberg S, Levy RI. Lipoprotein apoprotein metabolism. J Lipid Res. 1978; 19(6):667-87. [DOI:10.1016/ S0022-2275(20)41267-2]

[42] Carter LG, Lewis KN, Wilkerson DC, Tobia CM, Ngo Tenlep SY, Shridas $\mathrm{P}$, et al. Perinatal exercise improves glucose homeostasis in adult offspring. Am J Physiol Endocrinol Metab. 2012; 303(8):E1061-8. [DOI:10.1152/ajpendo.00213.2012] [PMID] [PMCID]

[43] Ros P, Díaz F, Freire-Regatillo A, Argente-Arizón P, Barrios $V$, Argente J, et al. Sex differences in long-term metabolic effects of maternal resveratrol intake in adult rat offspring. Endocrinology. 2020; 161(8):bqaa090. [DOI:10.1210/endocr/ bqaa090] [PMID]

[44] Napoli C, D'Armiento FP, Mancini FP, Postiglione A, Witztum $\mathrm{JL}$, Palumbo $\mathrm{G}$, et al. Fatty streak formation occurs in human fetal aortas and is greatly enhanced by maternal hypercholesterolemia. Intimal accumulation of low density lipoprotein and its oxidation precede monocyte recruitment into early atherosclerotic lesions. J Clin Invest. 1997; 100(11):2680-90. [DOI:10.1172/JCI119813] [PMID] [PMCID]

[45] Hopkins SA, Baldi JC, Cutfield WS, McCowan L, Hofman PL. Exercise training in pregnancy reduces offspring size without changes in maternal insulin sensitivity. J Clin Endocrinol Metab. 2010; 95(5):2080-8. [DOI:10.1210/jc.2009-2255] [PMID]

[46] Clapp 3rd JF. Morphometric and neurodevelopmental outcome at age five years of the offspring of women who continued to exercise regularly throughout pregnancy. J Pediatr. 1996; 129(6):856-63. [DOI:10.1016/S0022-3476(96)70029-X]

[47] Clapp 3rd JF. The effects of maternal exercise on fetal oxygenation and feto-placental growth. Eur J Obstet Gynecol Reprod Biol. 2003; 110(S1):S80-5. [DOI:10.1016/S03012115(03)00176-3]]

[48] Lalonde L, Gray-Donald K, Lowensteyn I, Marchand S, Dorais $M$, Michaels $G$, et al. Comparing the benefits of diet and exercise in the treatment of dyslipidemia. Prev Med. 2002; 35(1):16-24. [DOI:10.1006/pmed.2002.1052] [PMID] 
[49] Habibi Maleki A, Tofighi A, Ghaderi Pakdel F, Tolouei Azar J, Ehsani Far M. [Effect of three different exercise training modalities on blood lipid profile, fetuin-A, and fibroblast growth factor 21 (FGF-21) in visceral adipose tissue of obese rats (Persian)]. Jundishapur Sci Med J. 2020; 19(1):109-22 [DOI:10.22118/JSMJ.2020.209748.1923]

[50] Kinosian B, Glick H, Preiss L, Puder KL. Cholesterol and coronary heart disease: Predicting risks in men by changes in levels and ratios. J Investig Med. 1995; 43(5):443-50. [PMID] 